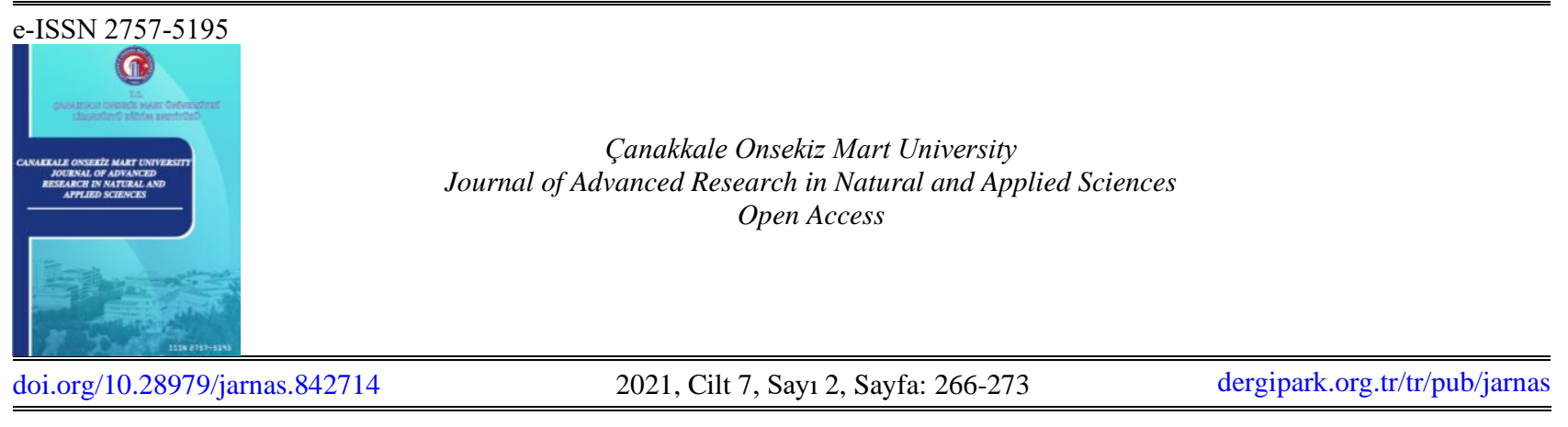

\title{
Lipid Productivity of Marine Microalgae Dunaliella tertiolecta in Marmara Seawater and Johnson's Media with Different Salinities and Evaluation as A Raw Material Source for Biofuel Production
}

\author{
Togayhan Kutluk ${ }^{1 *}$ \\ ${ }^{1}$ Department of Chemical Engineering, Faculty of Engineering, Kocaeli University, Kocaeli, Turkey \\ Article History \\ Received: $\quad 18.12 .2020$ \\ Accepted: $\quad 02.04 .2021$ \\ Published: $\quad 30.06 .2021$ \\ Research Article

\begin{abstract}
The valuable components from microalgae are increasingly used in the synthesis of several commercial chemicals. Lipids from major microalgae crops are similar to lipids obtained from oilseed plants and can be converted into biodiesel, moreover, microalgae are more advantageous than plants in oil production in many ways. Therefore, oil and biodiesel production technology from microalgae is a current and interesting research topic. The effect of salinity in the nutrient medium on the growth and lipid productivity of marine microalgae Dunaliella tertiolecta was examined. The usability of Marmara Seawater (MSW) as a growth medium and its suitability for microalgae were also investigated. The highest cell concentration $(1.53 \mathrm{gdw} / \mathrm{L})$, growth rate $\left(\mu_{\max }=0.006 \mathrm{~h}^{-1}\right)$ and oil productivity $(12.8$ $\left(\mathrm{g} / \mathrm{L}\right.$. Day) $\left.\left(10^{-3}\right)\right)$ in nutrient medium $(5 \mathrm{~g})$ were obtained. On the other hand, the cetane $(\mathrm{CN})$ number was calculated according to the dominant arachidic acid (C20:0), it was determined as 74.9 and the mean molecular weight of the oil was determined as $849.1 \mathrm{~g} / \mathrm{mol}$. According to the experimental results, it is predicted that microalgae lipids will be widely used as an alternative to vegetable oils soon as raw materials.
\end{abstract}

Keywords - Algae oil, biofuel, cetane number, dunaliella, fatty acids, microalgae, salinity

\section{Introduction}

Microalgae are unicellular microorganisms that are extensively found in marine and freshwater ecosystems. They are classified according to their shape, pigment content, and differences in their life cycle. Diatoms and blue-green microalgae show the most common distribution according to their abundance in nature (Chisti, 2007). Microalgae are used in different industrial areas with the valuable organic chemicals they contain, and microalgae biotechnology is becoming increasingly important today. The use of microalgae as cellular biofactories for the synthesis of valuable bioproducts for the aquaculture (fish feed), food, pharmaceutical, and biofuel sectors attracts high interest (Eryalçın et al., 2013; Kutluk, 2019). Microalgae are grown in closed (photobioreactor) or open (pool) systems. The production of valuable organic materials produced from microalgae is carried out using a light source (sun) and carbon dioxide photosynthetically. While outdoor pools are suitable for such production in tropical ecosystems, photobioreactors are used for microalgae production in countries that cannot utilize solar energy all day long. Also, recently, for high oil production from microalgae, using sugar and acetic acid as carbon sources, oil is obtained heterotrophically in a non-light environment (Ganuza \& Izquierdo, 2007). Three macromolecular compounds are extracted from microalgal biomass: fat, carbohydrate, and protein. These chemical compounds can be converted into fuels such as alcohol, biodiesel, green diesel, methane, and of the reaction of vegetable, algal, or animal origin oils with two main alcohol (methanol or ethanol) by a suitable catalyst. However, despite its many advantages such as biodiesel biodegradability and low emission characteristics, it still cannot be where it deserves commercially. The main reason for this is that the raw material (oil), which is the biggest cost item of biodiesel, is expensive (Mata et al., 2010). Otherwise, oils, which are major microalgae products, are similar to oils obtained from

\footnotetext{
1 (1) togay71@gmail.com

*Corresponding Author
} 
oilseed plants in terms of triglyceride content and can be converted into biodiesel (Knothe, 2010). The fact that the natural oil (lipid) form produced by microalgae is suitable for biofuel synthesis puts microalgae in a privileged place in this application (Stephens et al., 2010). Biomass extraction from microalgae, which is called the third generation energy source, has recently become important. Studies on obtaining lipids which are used as a raw material for biodiesel, from microalgae, which offer a potential to contribute to reducing dependence on fossil fuels, have increasingly continued in recent years. Lipid production mechanisms may change under different stress conditions (Nitrogen and Phosphorus restriction etc.) applied to the food environment of microalgae (Mata et al., 2010). The amount of lipid in microalgae generally varies between $20-50 \%$, in some of them, this ratio can be up to $80 \%$ (Halim et al., 2012). Dunaliella salina shows lipid accumulation which up to $70 \%$ of its cell content in response to high environmental salinity (Takagi \& Yoshida, 2006). Dunaliella $s p$., which is cultured in commercial levels in the world. The direct conversion of algae biomass to biodiesel raw material contributes to the economy (Pick \& Avidan, 2017). It has been reported that Dunaliella tertiolecta has a lipid capacity of 36-42\% (Tsukahara \& Sawayama, 2005). Dunaliella tertiolecta is a hopeful microorganism for alternative fuel applications for the synthesis of biodiesel for major reasons: its high salt tolerance, It is not affected by harsh climate conditions, and is not contaminated easily (Pick \& Avidan, 2017; Tang et al., 2011).

In this study, the Dunaliella tertiolecta species was selected considering factors such as its easy availability, specific morphological characteristics, resistance to contamination, adaptation to cold and heat, and different $\mathrm{pH}$ requirements. The influence of salinity in the nutrient medium on the growth and lipid productivity of marine microalgae were analysed. According to the author's knowledge for the first time in literature, the use of Marmara Seawater (MSW) as a growth medium and its suitability for microalgae were also investigated. Finally, Dunaliella tertiolecta was evaluated for utilization as a raw material for biodiesel synthesis.

\section{Materials and Methods}

\subsection{Materials}

Microalgae culture was gained from the culture collection of Dr.Turgay ÇAKMAK (İstanbul Medeniyet University /TURKEY). Johnson's nutrient medium and Marmara seawater with 24\% salinity was used as growth media. Johnson's media has been prepared using distilled water under laboratory conditions. "No nutrients have been added in MSW It was aimed to investigate that the microalgae species used in the study are grown in the synthetic environment and natural environment (MSW) and the effects of these environments on microalgae oil productivity. It Is Specified that in The Marmara Sea Report Published in 2016 by The Ministry of Environment and Urbanisation, In the MSW close to the coast section where it is in open waters in the range of $0.02-15.9 \mu \mathrm{M}, 0,05-0,53 \mu \mathrm{M} \mathrm{NO}_{2}+\mathrm{NO}_{3}-\mathrm{N}$ elements are specified respectively. The chemical composition of Johnson's medium and other solutions are shown in Table 1, Table 2, and Table 3.

Table 1

Chemical composition of Johnson's medium

\begin{tabular}{|c|c|c|c|}
\hline Chemical & Formula & $\begin{array}{c}\text { Molecular Weight } \\
(\mathrm{g} / \mathrm{mole})\end{array}$ & $\begin{array}{l}\text { Quantity } \\
\text { (g) }\end{array}$ \\
\hline Magnesium chloride hexahydrate & $\mathrm{MgCl}_{2} \cdot 6 \mathrm{H}_{2} \mathrm{O}$ & 203.30 & 1.5 \\
\hline Magnesium sulfate heptahydrate & $\mathrm{MgSO}_{4} \cdot 7 \mathrm{H}_{2} \mathrm{O}$ & 246.47 & 0.5 \\
\hline Potassium chloride & KCL & 74.55 & 0.2 \\
\hline Calcium chloride & $\mathrm{CaCl}_{2}$ & 110.98 & 0.2 \\
\hline Potassium nitrate & $\mathrm{KNO}_{3}$ & 101.10 & 1.0 \\
\hline Sodium bicarbonate & $\mathrm{NaHCO}_{3}$ & 84.01 & 0.043 \\
\hline Potassium dihydrogen phosphate & $\mathrm{KH}_{2} \mathrm{PO}_{4}$ & 136.09 & 0.035 \\
\hline
\end{tabular}

*Prepare $980 \mathrm{ml}$ and add 10 milliliters of iron solution (Table 2) and trace element solution (Table 3) to 1 liter. 
Table 2

Iron solution (for 1 Liter)

\begin{tabular}{l|lcc}
\hline \multicolumn{1}{c|}{ Chemical } & \multicolumn{1}{c}{ Formula } & $\begin{array}{c}\text { Molecular Weight } \\
(\mathrm{g} / \text { mole })\end{array}$ & $\begin{array}{c}\text { Quantity } \\
(\mathrm{g})\end{array}$ \\
\hline The ethylenediaminetetraacetic acid disodium salt & \multicolumn{1}{c}{$\mathrm{C}_{10} \mathrm{H}_{14} \mathrm{~N}_{2} \mathrm{Na}_{2} \mathrm{O}_{8} 2 \mathrm{H}_{2} \mathrm{O}$} & 372.24 & 1.89 \\
Ferric chloride hexahydrate & $\mathrm{FeCl}_{3} \cdot 6 \mathrm{H}_{2} \mathrm{O}$ & 270.30 & 2.44 \\
\hline
\end{tabular}

Table 3

Trace element solution (for 1 Liter)

\begin{tabular}{l|lcc}
\hline \multicolumn{1}{c|}{ Chemical } & \multicolumn{1}{c}{ Formula } & $\begin{array}{c}\text { Molecular Weight } \\
(\mathrm{g} / \mathrm{mole})\end{array}$ & $\begin{array}{c}\text { Quantity } \\
(\mathrm{mg})\end{array}$ \\
\hline Zinc chloride & \multicolumn{1}{c}{$\mathrm{ZnCl}_{2}$} & 136.30 & 4.1 \\
Boric acid & $\mathrm{H}_{3} \mathrm{BO}_{3}$ & 61.83 & 61.0 \\
Cobalt(II) chloride hexahydrate & $\mathrm{CoCl}_{2} \cdot 6 \mathrm{H}_{2} \mathrm{O}$ & 237.93 & 5.1 \\
Copper(II) chloride dihydrate & $\mathrm{CuCl}_{2} \cdot 2 \mathrm{H}_{2} \mathrm{O}$ & 170.48 & 4.1 \\
Manganese(II) chloride tetrahydrate & $\mathrm{MnCl}_{2} \cdot 2 \mathrm{H}_{2} \mathrm{O}$ & 197.91 & 4.1 \\
Ammonium molybdate tetrahydrate & $\left(\mathrm{NH}_{4}\right)_{6} \mathrm{Mo}_{7} \mathrm{O}_{24} 4 \mathrm{H}_{2} \mathrm{O}$ & 1235.86 & 38.0 \\
\hline
\end{tabular}

The salt source $\mathrm{NaCl}$ and other chemicals used in the study were in chromatographic purity and Merck brand. The prepared nutrient medium was sterilized in an autoclave at $121^{\circ} \mathrm{C}$ under 1 -atmosphere pressure for 20 minutes. Microalgae species were cultured under continuous illumination (at a light intensity of 3 Klux Osram Led) on IKA RCT brand magnetic stirrers set at $150 \mathrm{rpm}$ at room temperature.

\subsection{Microalgae Cultivation Under Different Salinities and Marmara Seawater}

Experiments were carried out in $100 \mathrm{ml}$ open flasks. Microalgae inoculating from stock cultures to 5\% of the growth medium. The starting temperature of cultures is set at $25 \pm 2{ }^{\circ} \mathrm{C}$. Temperature and $\mathrm{pH}$ were measured with a relative accuracy of $\pm 0.5^{\circ} \mathrm{C}$ and $\pm 0.001 \mathrm{pH}$ respectively with Mettler Toledo S20 SevenEasy model $\mathrm{pH}$ meter. The $\mathrm{pH}$ value of the medium was initially measured at 7.59. The culture's environments were naturally ventilated from the surface. The cell concentration and growth were determined spectrophotometrically at $600 \mathrm{~nm}$ using Jenway $6800 \mathrm{UV}$ Vis. Spectrophotometer. Different proportions of salt to Johnson's media $(5,10,30) \mathrm{g} / 100 \mathrm{ml}$. Also, MSW contains $24 \%$ salinity (Türkoğlu et al., 2004). Sea water samples were taken from Marmara Sea (Kocaeli Değirmendere with GPS coordinates $40^{\circ} 43^{\prime} 34.5^{\prime \prime} \mathrm{N}$ $29^{\circ} 47^{\prime} 40.0^{\prime \prime}$. The growth rate was determined according to Eq.2.1.

$\ln \frac{X}{X o}=\mu_{\text {net }} . t \quad$ or $\quad X=X_{0} e^{\mu_{\text {net. } t}}$

Where $\mu_{\text {net }}$ net specific growth rate, $X$, and Xo are cell concentration at $t$, and $t=0$. Doubling time of the microorganism determined by Eq. 2.2.

$\tau_{d}=\frac{\ln 2}{\mu_{n e t}}=\frac{0.693}{\mu_{n e t}}$

\subsection{Microalgae Sampling and Harvesting}

Samples of $3 \mathrm{ml}$ were collected regularly from culture media for $\mathrm{pH}$, temperature, and absorbance measurements. Microalgae removed from the liquid media by centrifuge $(5000 \mathrm{rpm} / 5 \mathrm{~min})$ and then dried in an $80^{\circ} \mathrm{C}$ oven per night. The experimental system was repeated 2 times. The number of dry microalgae (gdw/L) obtained from $100 \mathrm{ml}$ flasks after harvesting is given in Table 4. 
Table 4

Effect of different salinities on growth and lipid content for Dunaliella tertiolecta

\begin{tabular}{c|ccccc}
\hline $\begin{array}{c}\text { Salinity } \\
(\mathrm{g})\end{array}$ & $\begin{array}{c}\mathrm{X}_{\max } \\
(\mathrm{gdw} / \mathrm{L})\end{array}$ & $\begin{array}{c}\mu \max \\
(\mathrm{h}-1)\end{array}$ & $\begin{array}{c}\text { Doubling Time } \\
(\mathrm{h})\end{array}$ & $\begin{array}{c}\text { Fat content } \\
(\%)\end{array}$ & $\begin{array}{c}\text { Lipid productivity } \\
(\mathrm{g} / \mathrm{L} . \mathrm{day})\left(10^{-3}\right)\end{array}$ \\
\hline 5 & 1.53 & 0.06 & 11.6 & 15 & 12.8 \\
10 & 1.12 & 0.05 & 13.9 & 12 & 7.4 \\
$\operatorname{MSW}(24)$ & 0.99 & 0.06 & 11,6 & 7 & 3.8 \\
30 & 0.72 & 0.05 & 13.9 & 5 & 2.0 \\
\hline
\end{tabular}

\subsection{Lipid and Fatty Acid Profile Analyses}

$20 \mathrm{ml}$ of a $0.4 \% \mathrm{CaCl}_{2}$ solution on a $0.2 \mathrm{~g}$ sample was added to $120 \mathrm{ml}$ of methanol /chloroform $1 / 2$ and then stirred on a magnetic stirrer for three hours. After, the drained samples from the filter paper (Whatman No: 1) were stored in the filter for two hours at $105^{\circ} \mathrm{C}$ and filtered through the flasks. The mouths of the balloons were closed in an air-tight manner and kept in a dark place for one night and the next day the top layer consisting of methanol-water was collected with the help of a separating funnel. The chloroform remaining in the bubbles was evaporated from the lipid to chloroform at $60^{\circ} \mathrm{C}$ in the dryer. The balloons were then allowed to stand at $90^{\circ} \mathrm{C}$ for one hour to allow the entire chloroform to evaporate and cooled to $25^{\circ} \mathrm{C}$ in the desiccator. The mass of the oil was specified gravimetrically (Bligh \& Dyer, 1959). Microalgae oil content was determined according to Eq. 2.3.

Oil content $\%=\frac{[\text { Flask tare }(\mathrm{g})+\mathrm{Lipid}(\mathrm{g})]-[\text { Flask tare }(\mathrm{g})]}{\text { Sample amount }(\mathrm{g})} \times 100$

The fatty acid composition was determined in gas chromatography (Agilent GC 7820) with the help of Agilent application notes. Analysis conditions are clearly stated in the application notes (David et al., 2005). No internal standard was used in GC analysis.

\subsection{Cetane Number $(\mathrm{CN})$ Identification}

Fatty acids $\mathrm{CN}$ of oils obtained from microalgae were calculated according to Eq.2.4 (Klopfenstein, 1982).

$\mathrm{CN}=58.1+[(1.4) \times(\mathrm{n}-8)]-[15.9 \times($ double bond number $)]$

$n$ indicates that the number of carbons in fatty acid

\section{Results and Discussion}

\subsection{Microalgae Growth Behaviour}

Important parameters affecting microorganism culture growth or cultivation; nutrient quality and quantity of the medium, light, $\mathrm{pH}$, salinity, and temperature. These parameters can vary by species. The parameter, which is optimum in the environmental conditions created in the studies, may not be optimum for another environment (Chisti, 2007). The salinity value varies according to the microalgae species (Mata et al., 2010). The time-dependent growth of Dunaliella tertiolecta in photobioreactors under the influence of different salinities is shown in Figure 1.

For Dunaliella tertiolecta, as can be seen from Figure 1, microorganism growth in all media increased at different rates until the 96th hour. From this hour until the 240th hour, microorganism cell concentrations increased at low rates, after the 240th hour the growth increased a little more until the 384th hour and after this time it switched to the stagnant phase. The microorganism adapted to all conditions and showed a tendency to grow at different growth rates. 
After 18 days of culture, the highest cell concentration $(1.53 \mathrm{gdw} / \mathrm{L})$, growth rate $\left(\mu_{\max }=0.006 \mathrm{~h}^{-1}\right)$ and oil productivity $\left(12.8\left(\mathrm{~g} / \mathrm{L}\right.\right.$. Day) $\left.\left(10^{-3}\right)\right)$ in nutrient medium $(5 \mathrm{~g})$ were reached (Table 4$)$. Microalgae oil from Dunaliella Tertiolecta is shown in Figure 2.

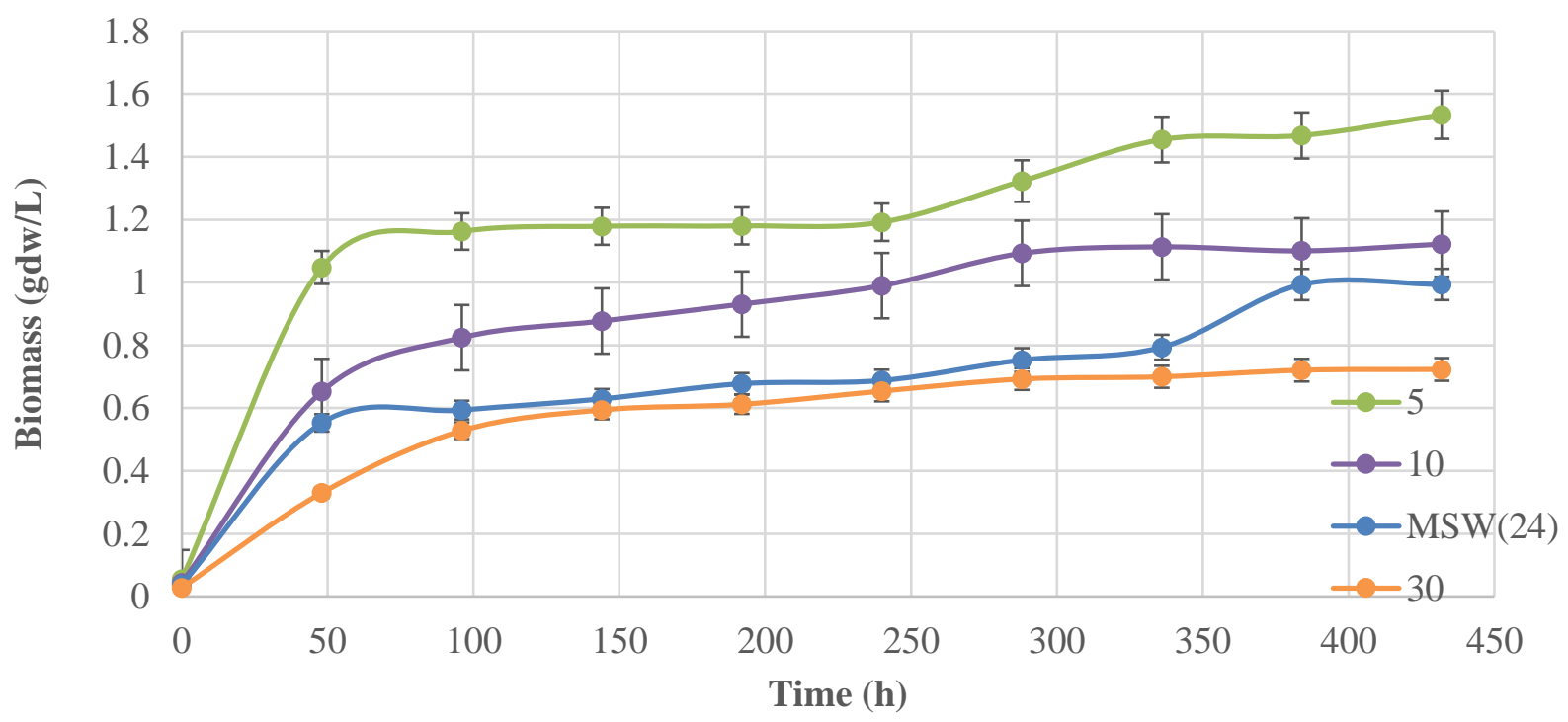

Figure 1. Dunaliella tertiolecta growth curve under different salinities

It was determined that with the increase of salt starvation in the growth media the oil production within the microorganism also increased. According to the author's knowledge, limited studies are examining the behavior and lipid production potential of Dunaliella tertiolecta under salt starvation. A comparable single study, Hopkins et al. (2019) reported that the lipid which they obtained from microalgae was suitable as a raw material source for biofuel manufacture. Besides by reaching the highest cell concentration for Dunaliella species in $\mathrm{f} 2$ nutrient media containing $120 \mathrm{~g} / \mathrm{L}$ salinity. The $\mathrm{pH}$ changes of the photobioreactors during the culture are given in Figure 3.

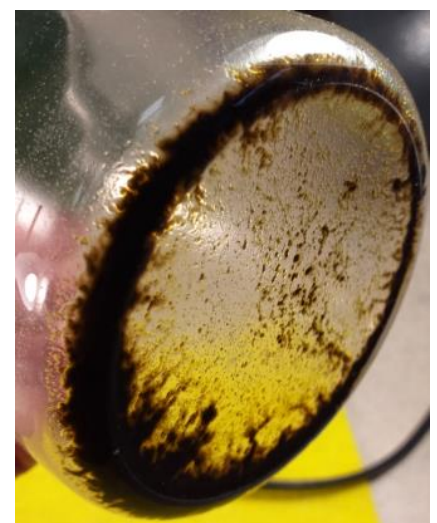

Figure 2. Microalgae oil from Dunaliella tertiolecta

During the culture, an increase was observed in $\mathrm{pH}$ values depending on the growth and after the 384th hour, it changed between 10.2 and 10.6 with small fluctuations. In autotrophic cultures, microalgae use inorganic carbon and release hydroxyl into the environment. Therefore, the $\mathrm{pH}$ of the environment is expected to rise and be stable after a certain time (Kutluk, 2019). As can be seen from Figure 2, the initial pH of the environment is around 7.5 for each culture. 


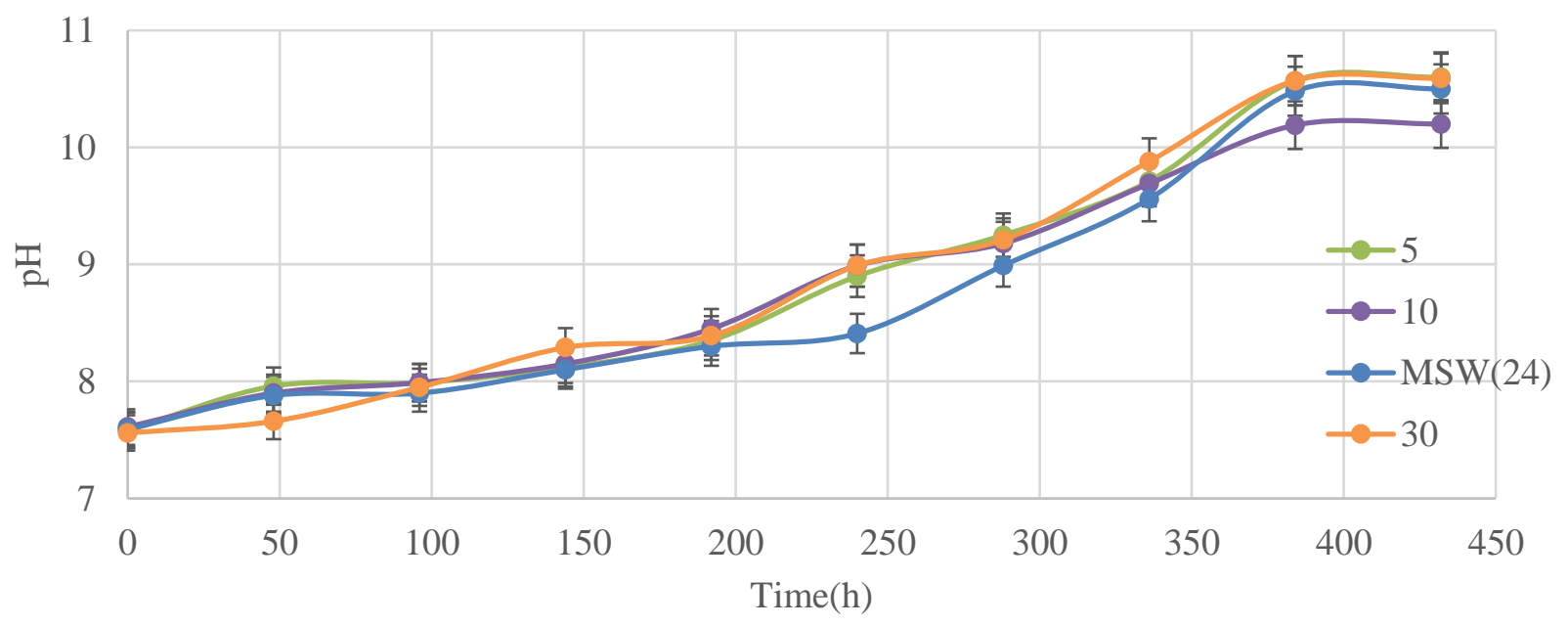

Figure 3. pH distribution in cultures under the different salinities

\subsection{Fatty Acid Distribution of Dunaliella tertiolecta}

The fatty acid dispersion and the amount of fat synthesis by microalgae vary by species. Fatty acid compositions or profiles may also vary depending on the physical (light, temperature) and chemical (compounds in the nutrient media) conditions of the growing medium. Generally, the fatty acids of microalgae species vary between C12 and C22. In some species, the upper limit can be up to C24 (Halim et al., 2012). The fatty acid profile of Dunaliella tertiolecta microalgae is given in Table 5.

Table 5

Fatty acid compositions of Dunaliella tertiolecta

\begin{tabular}{l|c}
\hline \multicolumn{1}{c|}{ Type of fatty acid } & Percentage \% \\
\hline C17:0 Heptadecanoic & 8.6 \\
C18:1 Oleic & 17.8 \\
C18.2 Linoleic & 25.3 \\
C18:3 a-Linoleic & 9.4 \\
C20:0 Arachidic & 30.2 \\
C20:1Eicosenoic acid & 8.7 \\
\hline
\end{tabular}

The fatty acid dispersion of the microalgae oil changes between $\mathrm{C} 17$ and C20:1. The CN was calculated according to the dominant arachidic acid, it was determined as 74.9 and the mean molecular weight of the oil was determined as $914.3 \mathrm{~g} / \mathrm{mol}$. CN is very high. It is expected that methyl or ethyl esters (biodiesel) to be obtained from this oil can be easily ignited and burned rapidly.

$\mathrm{CN}$ is major characteristics determining the ignition quality of the fuel to be used in a diesel engine. $\mathrm{CN}$ of esters of edible oils than diesel fuel higher (Krisnangkura, 1986). The diesel fuel CN is between 55 and 60 . The $\mathrm{CN}$ in biodiesel varies between 55 and 75 , the $\mathrm{CN}$ of biodiesel is higher than diesel as can be seen (Klopfenstein, 1982). Fuel with a high CN is easily flammable and can burn quickly. A comparable study with the same microalgae species Hopkins et al. (2019) reported that the fatty acid dispersion of the microalgae oil is rich in $\mathrm{C} 16$ and $\mathrm{C} 18$. They have also demonstrated its suitability for biodiesel production. 


\section{Conclusion}

In this study, the influence of salinity in the nutrient medium on the cultivation and lipid productivity of marine microalgae was investigated. The usability of Marmara Seawater (MSW) as a growth medium and its suitability for microalgae were also investigated. Finally, Dunaliella tertiolecta was evaluated for utilization as a feedstock for biofuel industries.

From the obtained experimental data, it is possible to draw some conclusions from this study;

- After 18 days of culture, the highest cell concentration $(1.53 \mathrm{gdw} / \mathrm{L})$, growth rate $\left(\mu \mathrm{max}=0.006 \mathrm{~h}^{-1}\right)$ and oil productivity $\left(12.8\right.$ (g/L.Day) $\left.\left(10^{-3}\right)\right)$ in nutrient medium $(5 \mathrm{~g})$ were reached.

- The $\mathrm{CN}$ and molecular weight of the oil were calculated according to the dominant arachidic acid (C20:0), it was determined as 74.9 and $849.1 \mathrm{~g} / \mathrm{mol}$ respectively.

The results obtained from this study are promising for future studies and environmentally friendly industrial enterprises that are planned to be established. Besides, it is predicted that microalgae lipids will be widely used as an alternative to vegetable oils soon as raw materials.

\section{Acknowledgment}

The author thanks Prof. Dr. Turgay ÇAKMAK for providing microalgae culture.

\section{Author Contributions}

Togayhan KUTLUK: Conceived and designed the analysis, Collected data, performed the analysis, and wrote the paper.

\section{Conflicts of Interest}

The author declares that have no known competing financial interests or personal relationships that could have appeared to influence the work reported in this paper.

\section{References}

Bligh, E. G., \& Dyer, W.J. (1959). A Rapid Method of Total Lipid Extraction and Purification. Canadian journal of biochemistry and physiology, 37(8), 911-917. DOI:https://doi.org/10.1139/o59-099

Chisti, Y. (2007). Biodiesel from Microalgae. Biotechnology Advances, 25(3), 294-306. https://doi.org/10.1016/j.biotechadv.2007.02.001

David, F., Sandra, P. \& Vickers, A.K. (2005). Column selection for the analysis of fatty acids methyl esters. Application Agilent Technologies Incorporation. Retrieved from: https://www.agilent.com/cs/library/applications/5989-3760EN.pdf

Eryalçın, K. M., Roo, J., Saleh, R., Atalah, E., Benítez, T., Betancor, M. \&Izquierdo, M. (2013). Fish oil replacement by different microalgal products in micro diets for early weaning of gilthead sea bream (Sparusaurata, L.). Aquaculture Research, 44(5), 819-828. DOI:https://doi.org/10.1111/j.13652109.2012.03237.x

Ganuza, E. \& Izquierdo, M. (2007). Lipid accumulation in Schizochytrium G13/2S produced in continuous culture. Applied Microbiology and Biotechnology, 76, 985-990. DOI:https://doi.org/10.1007/s00253007-1019-4

Halim, R., Danquah, M. K., Webley, P. A. (2012). Extraction of Oil from Microalgae for Biodiesel Production: A review. Biotechnology Advances, 30(3), 709-732. DOI:https://doi.org/10.1016/j.biotechadv.2012.01.001

Hopkins, T.C., Sullivan Graham, E.J. \& Schuler, A.J. (2019). Biomass and lipid productivity of Dunaliellatertiolecta in a produced water-based medium over a range of salinities. Journal of Applied Phycology, (31), 3349-3358. DOI: https://doi.org/10.1007/s10811-019-01836-3

Klopfenstein, W. E. (1982). Estimation of Cetane Index for Esters of Fatty Acids. Journal of American Oil Chemists Society, 59(12), 531-533.DOI: https://doi.org/10.1007/BF02636316

Knothe, G. (2010). Biodiesel and renewable diesel: A comparison. Progress in Energy and Combustion Science, 36, 364-373. DOI:https://doi.org/10.1016/j.pecs.2009.11.004 
Krisnangkura, K. (1986). A Simple Method for Estimation of Cetane Index of Vegetable Oil Methyl Esters. Journal of American Oil Chemists Society, 63(4), 552-553. DOI:https://doi.org/10.1007/BF02645752

Kutluk, T. (2019). Production of Different Chlorella Species used in Biodiesel and Waste Water Treatment. (Ph.D. thesis). Retrieved from: https://tez.yok.gov.tr/UlusalTezMerkezi

Mata, M.T, Martinas, A.A. \& Caetano, N.S. (2010). Microalgae for biodiesel production and other applications: A review. Renewable and Sustainable Energy Reviews, 14,217-232. DOI:https://doi.org/10.1016/ j.rser.2009.07.020

Mata, T. M., Martins, A. A., \& Caetano N.S. (2010). Microalgae for biodiesel production and other applications: A review. Renewable Sustainable Energy Reviews, 14(1), 217-232. DOI:https://doi.org/ 10.1016/j.rser.2009.07.020

Pick, U. \&Avidan, O. (2017). Triacylglycerol is produced from starch and polar lipids in the green alga $\mathrm{Du}$ naliellatertiolecta.Journal of Experimental Botany, 68(17), 4939-4950. DOI:https://doi.org/10.1093/jxb/erx280

Stephens, E., Ross, I.L., Mussgnug, J.H., Wagner, L.D., Browitzka, M.A., Posten, C., Kruse, O. \&Hankamer, B. (2010). Future prospects of microalgal biofuel production systems. Trends in Plant Science, 15, 554564.DOI:https://doi.org/10.1016/j.tplants.2010.06.003

Takagi, M. \& Yoshida, T. (2006). Effect of salt concentration on intracellular accumulation of lipids and triacylglyceride in marine microalgae Dunaliella cells. Journal of Bioscience and Bioengineering, 10, 223-226. DOI:https://doi.org/10.1263/jbb.101.223

Tang, H., Abunasser, N., Garcia, M.E.D., Chen, M., Simon, K.Y. \&Salley, S.O. (2011). Potential of microalgae oil from Dunaliellatertiolecta as a feedstock for biodiesel. Applied Energy, 88:3324-3330. https://doi.org/10.1016/j.apenergy.2010.09.013

Tsukahara, K. \&Sawayama, S. (2005). Liquid Fuel Production using Microalgae. Journal of the Japan Petroleum Institute, 48(5), 251-259. DOI:https://doi.org/10.1627/jpi.48.251

Türkoğlu, M., Yenici, E., İşmen, A., \& Kaya, S. (2004). Variations of nutrient and chlorophyll-a in the Çanakkale Strait (Dardanelles). Ege Journal of Fisheries \& Aquatic Sciences 21, 93-98. Retrieved from: http://www.egejfas.org/tr/download/article-file/57874 